\title{
Music and musical sonification for the rehabilitation of Parkinsonian dysgraphia: Conceptual framework
}

\author{
Lauriane Véron-Delor ${ }^{1,2}$, Serge Pinto ${ }^{2}$, Alexandre Eusebio ${ }^{3}$, Jean-Luc Velay ${ }^{1,2}$, \\ Jérémy Danna ${ }^{1,2}$, \\ ${ }^{1}$ Aix Marseille Univ, CNRS, LNC, Marseille, France \\ jean-luc.velay@univ-amu.fr; jeremy.danna@univ-amu.fr \\ 2 Aix Marseille Univ, CNRS, LPL, Aix-en-Provence, France \\ lauriane.veron-delor@univ-amu.fr; serge.pinto@univ-amu.fr \\ ${ }^{3}$ Aix Marseille Univ, CNRS, INT, Marseille, France \\ alexandre.eusebio@univ-amu.fr
}

\begin{abstract}
Music has been shown to enhance motor control in patients with Parkinson's disease (PD). Notably, musical rhythm is perceived as an external auditory cue that helps PD patients to better control movements. The rationale of such effects is that motor control based on auditory guidance would activate a compensatory brain network that minimizes the recruitment of the defective pathway involving the basal ganglia. Would associating music to movement improve its perception and control in PD? Musical sonification consists in modifying in real-time the playback of a preselected music according to some movement parameters. The validation of such a method is underway for handwriting in PD patients. When confirmed, this study will strengthen the clinical interest of musical sonification in motor control and (re)learning in PD.
\end{abstract}

Keywords: Movement sonification; Cueing; Feedback; Handwriting; Parkinson's disease.

\section{Introduction: external cueing and feedback as part of rehabilitation in Parkinson's disease}

Parkinson's disease (PD) is the second most common neurodegenerative disorder after Alzheimer's disease. It is caused by the loss of dopaminergic neurons in the pars compacta of the substantia nigra and other neurological systems, leading to a set of motor and non-motor symptoms [1]. PD symptoms are managed with medication (e.g., L-Dopa, dopaminergic agonists) and/or neurosurgical interventions, including mainly deep brain stimulation. Nevertheless, limitations of such treatments to relieve motor disturbances have led to investigate non-pharmacological additional methods based on assisted motor rehabilitation. Among the various methods of motor rehabilitation, there is a growing interest in applying external cues and/or supplementary feedback to supplement drugs-based approaches.

Gait (for reviews, see [2] and [3]), and, to a lesser extent, handwriting (for a review, see [4]) were particularly brought into focus. The present chapter aims at 
reporting and questioning the studies carried out in the last decade and for which the effect of rehabilitation based on feedback or on auditory cueing was evaluated in Parkinsonian walking or handwriting (see Table 1).

Table 1. Auditory cueing- or feedback-based studies on gait, tapping, and writing in PD.

\begin{tabular}{|c|c|c|c|c|}
\hline \multicolumn{5}{|c|}{ Auditory cueing-based rehabilitation studies } \\
\hline Ref & Subjects & Conditions & Data analysis & Main results \\
\hline [5] & $\begin{array}{l}15 \text { PD ON } \\
\& 20 \text { CTL }\end{array}$ & $\begin{array}{l}12 \text { trainings } \\
\text { Individualised RAS at } 3 \\
\text { tempos, embedded in a } \\
\text { musical structure }\end{array}$ & $\begin{array}{l}\text { BAASTA; } \\
\text { Stride length }\end{array}$ & $\begin{array}{l}\text { Improvement in } \\
\text { synchronization and hand } \\
\text { tapping after training }\end{array}$ \\
\hline [6] & $\begin{array}{l}22 \text { PD ON } \\
\text { in } 2 \text { groups }\end{array}$ & $\begin{array}{l}39 \text { trainings } \\
\text { Individualised music vs. no } \\
\text { music }\end{array}$ & $\begin{array}{l}\text { Gait velocity; } \\
\text { Stride time; } \\
\text { Stride length; } \\
\text { Cadence }\end{array}$ & $\begin{array}{l}\text { Improvement of gait } \\
\text { velocity, stride time and } \\
\text { cadence following music } \\
\text { training }\end{array}$ \\
\hline [7] & 12 PD OFF & $\begin{array}{l}\text { Two tasks: walking then } \\
\text { walking + carrying a cup full } \\
\text { of water, under } 4 \text { conditions: } \\
\text { No cue vs. Visual (transverse } \\
\text { strips) vs. Auditory } \\
\text { (metronome) vs. visual and } \\
\text { auditory cues }\end{array}$ & $\begin{array}{l}\text { Freezing } \\
\text { number and } \\
\text { duration; } \\
\text { Cadence; } \\
\text { Gait velocity; } \\
\text { Stride length }\end{array}$ & $\begin{array}{l}\text { Improvement of cadence and } \\
\text { stride length with visual and } \\
\text { dual cues in both tasks } \\
\text { Improvement of FOG with } \\
\text { all types of cues in both tasks }\end{array}$ \\
\hline [8] & $\begin{array}{l}14 \text { PD ON } \\
\& 20 \text { CTL }\end{array}$ & $\begin{array}{l}12 \text { trainings } \\
\text { - Individualised RAS at } 2 \\
\text { tempos, embedded in a } \\
\text { musical structure }\end{array}$ & $\begin{array}{l}\text { BAASTA; } \\
\text { Gait velocity; } \\
\text { Stride length; } \\
\text { Cadence; } \\
\text { Synchronizat } \\
\text { ion } \\
\text { variability }\end{array}$ & $\begin{array}{l}\text { Improvement of PD gait } \\
\text { parameters (velocity and } \\
\text { stride length) directly and } 1 \\
\text { month after training }\end{array}$ \\
\hline [9] & $15 \mathrm{PD} O \mathrm{ON}$ & $\begin{array}{l}\text { Two tasks (digital tapping }+ \\
\text { foot tapping) under } 2 \\
\text { conditions: No cue vs. } \\
\text { auditory cue (metronome) }\end{array}$ & $\begin{array}{l}\text { Freezing } \\
\text { duration; } \\
\text { Tapping } \\
\text { frequency; } \\
\text { Tapping } \\
\text { amplitude }\end{array}$ & $\begin{array}{l}\text { Metronome decreased the } \\
\text { frequency and the incidence } \\
\text { of freezing, and improved } \\
\text { both digital and foot tapping } \\
\text { frequency }\end{array}$ \\
\hline [10] & $\begin{array}{l}58 \text { PD ON } \\
\text { in } 3 \text { groups }\end{array}$ & $\begin{array}{l}60 \text { dance lessons } \\
\text { Tango vs. Waltz/foxtrot vs. } \\
\text { Nothing }\end{array}$ & $\begin{array}{l}\text { Balance; Gait } \\
\text { velocity; } \\
\text { Forward and } \\
\text { backward } \\
\text { walking; }\end{array}$ & $\begin{array}{l}\text { Improvement in balance, gait } \\
\text { velocity and backward } \\
\text { walking in both dance } \\
\text { groups } \\
\text { Greater improvement with } \\
\text { tango }\end{array}$ \\
\hline [11] & $\begin{array}{l}75 \text { PD ON } \\
\text { in } 4 \text { groups }\end{array}$ & $\begin{array}{l}40 \text { dance lessons } \\
\text { Tango vs. Waltz/foxtrot vs. } \\
\text { Tai Chi vs. Nothing }\end{array}$ & HRQoL & $\begin{array}{l}\text { Improvement in } \mathrm{HRQoL} \\
\text { only after tango }\end{array}$ \\
\hline [12] & $\begin{array}{l}20 \text { PD ON } \\
\text { in } 2 \text { groups }\end{array}$ & $\begin{array}{l}3 \text { trainings } \\
\text { SDTT vs. RAC }\end{array}$ & $\begin{array}{l}\text { Gait velocity; } \\
\text { Cadence; }\end{array}$ & $\begin{array}{l}\text { RAC improved gait speed } \\
\text { and SDTT improved balance }\end{array}$ \\
\hline
\end{tabular}


[13] 47 PD ON 8 days training in 2 groups RAS vs. No cue

[14] 25 PD ON Walking session under 3 (with vs. conditions: Visual without (transverse strips) vs. FOG) \& 10 Auditory (metronome) vs. CTL No cue

[15] 10 PD OFF Walking session under 2 conditions: No cue vs. RAS (metronome)

[16] 9 PD ON Walking session under 3 conditions: No cue vs. CUET vs. CUEST

[17] 10 PD ON 3 walking sessions: \& 10 CTL Session 1 under 4 conditions: Verbal instruction vs. verbal instruction + metronome vs. HFGS vs. HFGS + verbal instruction

Session 2 under 4 conditions: HFGS vs. HFGS

+ verbal instruction vs. synthesized footstep sounds vs. synthesized footstep sounds + verbal instruction

Session 3 under 4 conditions: HFGS vs. mental imagery of HFGS vs. synthesized footstep sounds vs. mental imagery of synthesized footstep sounds

[18] 19 PD OFF Walking session under 4 (with vs.
Balance; Retention effects founded 3-

HRQoL month after both RAC and SDTT training

FOG Improvement of all gait

number; Gait parameters after RAS

velocity; training

Stride length

FOG Improvement in gait and

number; Step FOG number with visual cue number in PD FOG only

No effect of auditory cue in PD FOG

Better improvement in gait with auditory cues for PD without FOG than for PD FOG

Gait velocity; Improvement in all gait Stride length; parameters after RAS Cadence training

Gait velocity Improvement of gait and velocity, stride amplitude variability; and cadence with both Stride CUET and CUEST, the latter amplitude; being the most effective Cadence Stride length Decrease of stride length and variability in PD patients variability; during session with HFGS Velocity; and HFGS + verbal Cadence; instruction

Gait variability Improvement in stride length in all conditions except in synthesized sounds condition PD patients fail to adapt to the synthesized footstep sounds

Performances are better during cueing than during imagery

Performances are better during mental imagery of HFGS than during mental imagery of synthesized footstep sounds

Step time No cueing effect in PD variability; without FOG 
without on a corridor sounds vs. FOG) metronome vs. healthy footstep on gravel sounds vs. synthesized footstep sound
Swing time Improvement in temporal variability; regularity in PD with FOG in Rhythmicity; forth conditions Asymmetry

\begin{tabular}{|c|c|c|}
\hline & & Auditory feedback-base \\
\hline [19] & 16 PD ON & $\begin{array}{l}\text { Walking session: Clicking } \\
\text { sound in response to every } \\
\text { step }\end{array}$ \\
\hline [20] & $\begin{array}{l}42 \text { PD ON } \\
\text { (with vs. } \\
\text { without } \\
\text { FB) }\end{array}$ & $\begin{array}{l}20 \text { trainings with visual } \\
\text { movement } F B, \text { visual color } \\
\text { target } F B \text { and auditory } \\
\text { target } F B\end{array}$ \\
\hline
\end{tabular}

\section{rehabilitation studies}

Cadence; Improvement in speed and stride length stride length during and after training with $\mathrm{FB}$

Clinical motor Improvement in balance evaluations during and 1 month after experimental training No change in without FB group

\begin{tabular}{|c|c|c|c|c|}
\hline \multicolumn{5}{|c|}{ Auditory cueing- and feedback-based rehabilitation studies } \\
\hline [21] & $\begin{array}{l}28 \text { PD ON } \\
\text { (with vs. } \\
\text { without } \\
\text { FOG) }\end{array}$ & $\begin{array}{l}6 \text { weeks trainings under } 4 \\
\text { conditions: RAS vs. IC vs. } \\
\text { IF vs. No cue/FB }\end{array}$ & $\begin{array}{l}\text { Gait } \\
\text { deviations }\end{array}$ & $\begin{array}{l}\text { Gait deviations decrease with } \\
\text { RAS in PD with FOG }\end{array}$ \\
\hline [22] & $\begin{array}{l}11 \mathrm{PD} \mathrm{ON} \\
\& 11 \mathrm{CTL} \\
\& 11 \mathrm{CTL} \\
\text { young }\end{array}$ & $\begin{array}{l}\text { Walking session under } 4 \\
\text { conditions: no cue vs. } \\
\text { auditory cue vs. verbal } \\
\text { instruction vs. COM } \\
\text { (auditory cue and verbal } \\
\text { instruction) }\end{array}$ & $\begin{array}{l}\text { Gait velocity; } \\
\text { Stride length; } \\
\text { Cadence }\end{array}$ & $\begin{array}{l}\text { Improvement of gait velocity } \\
\text { and stride length with verbal } \\
\text { feedback and COM }\end{array}$ \\
\hline [23] & $\begin{array}{l}15 \mathrm{PD} \mathrm{ON} \\
\& 15 \mathrm{CTL} \\
\& 15 \mathrm{CTL} \\
\text { young }\end{array}$ & $\begin{array}{l}\text { Unimanual and bimanual } \\
\text { drawing sessions under } 3 \\
\text { conditions: visual cue vs. } \\
\text { auditory FB vs. verbal FB }\end{array}$ & $\begin{array}{l}\text { Amplitude; } \\
\text { Amplitude } \\
\text { variability; } \\
\text { Coordination; } \\
\text { Precision }\end{array}$ & $\begin{array}{l}\text { Improvement of coordination } \\
\text { and amplitude variability } \\
\text { with both auditory and } \\
\text { verbal feedback }\end{array}$ \\
\hline [24] & $206 \mathrm{PD}$ ON & $\begin{array}{l}4 \text { weeks treadmill training } \\
\text { with visual and auditory FB } \\
\text { and cues }\end{array}$ & $\begin{array}{l}\text { Steps length; } \\
\text { Cadence; } \\
\text { Coefficient of } \\
\text { variance of } \\
\text { both steps }\end{array}$ & $\begin{array}{l}\text { Improvement of step length } \\
\text { and variability, and cadence }\end{array}$ \\
\hline
\end{tabular}

Abbreviations: PD: Individuals with PD; ON: on-medication; OFF: off-medication; CTL: Control subject; RAS: Rhythmic auditory stimulation; BAASTA: Battery for the assessment of auditory sensorimotor and timing abilities, including timing perception, discrimination and synchronization; HRQoL: Health related quality of life; SDTT: Speed-dependent treadmill training; RAC: Rhythmic auditory cue, individualised music playlist and metronome; FOG: Freezing of gait; CUET: Cue temporal, metronome with temporal instruction "As you walk try to step in time to the beat"; CUEST: Cue spatiotemporal, metronome with spatiotemporal instruction "As you walk try to take a big step in time to the beat"; HFGS: Healthy footstep on gravel sounds; IC: Intelligent cueing (auditory rhythm signal when strides deviated more than $5 \%$ from the reference cadence); IF Intelligent feedback (verbal instruction to speeding or slowing); FB: Feedback; COM: Combined information auditory cue and verbal instruction. 
The organization and production of movement involves the integration of sensory information, which can be considered as basic feedback. Basic feedback informs about both the environment and the current state of the body to determine the appropriate set of muscle forces to generate the desired movement. Thus, a deficit in the processing of basic feedback affects the initiation of movements. Vision and/or audition are the most commonly used sensory modalities to support initiation and control of movement. They are differentially specialized to encode information from the environment and our body, visual information being more relevant for spatial processing, and auditory information for temporal processing [25].

On the one hand, supplementary feedback enriches the perception of selfperformance during or after movement production, mainly based on internal expectations/representations. Supplementary feedback can provide information about the outcomes of an action with respect to the environmental goal or about the process, i.e. the movement produced. The terms of "knowledge of results" and "knowledge of performance" are respectively employed [26]. On the other hand, external cues yield a point of reference to guide movements execution [27]. In the field of motor rehabilitation with PD patients, the use of auditory cues has been largely preferred, especially for improving gait (e.g., [2] and [28]) and speech (e.g., [29] and [30]) disorders. Such enthusiasm is certainly justified by the natural and spontaneous tendency in humans to synchronize action with rhythm [31]. Very promising, and sometime unexpected, effects have been observed with the use of rhythmic auditory stimulation (RAS; see table 1 - e.g., [8]). PD patients are tempted to couple their steps to RAS provided by a metronome or an amplified beat of a music. Some researches reveal improvements with RAS in gait velocity and stride length, sometimes with long-term benefits [8] and [13]. Music itself carries an intrinsic rhythm that plays the role of an external cue (e.g., [32]), as a metronome, guiding movements. Moreover, music contributes to something more than simple metronome rhythm: emotional aspects are conveyed with the melody, especially when the music is familiar. Music involves both cognitive and emotional processing, which can be used to carry over effects (e.g., mental singing - [33]). In healthy individuals, Wittwer and colleagues [34] have compared effects of rhythmic music and metronome as external cuing on gait. They showed that music might be more efficient than the metronome to improve the velocity and cadence of gait, due to emotional aspects and motivation ensuing by melody. In individuals with PD, it has been shown that continuous sounds, like music, lead to better gait fluency than a simple metronome (see table 1, [18]).

\section{Why does supplementary feedback or external cueing facilitate motor (re)learning for individuals with PD?}

Movement rehabilitation in PD aims at improving motor control and coordination by either strengthening pre-existing pathways [27] or creating alternative circuits bypassing the basal ganglia. Motor learning is possible in individuals with PD (for a review, see [4]). Such concept raises the question of brain neuroplasticity. Neuroplasticity encompasses the ability for healthy neural networks to form new synapses in order to bypass and reorganize the damaged network [27]. Any functional 
motor rehabilitation is based on this phenomenon and may facilitate neurological recovery [35]. Neuroplasticity is stimulated by frequent motor or cognitive activities. Nevertheless, it is slowed down in individuals with PD compared to healthy subjects. This must be taken into account in the rehabilitation duration [4].

Distinct phases, consolidation, automatization, and retention, are identified in the process of motor learning. Doyon \& Benali [36] revisited a model describing the brain plasticity during motor learning. According to this model, a clear distinction is proposed between motor sequence learning (MSL), which characterizes the process by which practice turns a sequence of actions into a behaviour, and motor adaptation (MA), which is required in response to environmental changes. Motor learning goes along with a decrease of cortical activity, especially in prefrontal and parietal regions that are involved in attentional processing of sensory information. At the same time, the activation of the cerebellum and basal ganglia increase according to the type of motor task, MA and MSL, respectively [37].

PD affects the functioning of the striato-thalamo-cortical loop (Figure 1, dotted arrows), particularly involved in the control of learned movements. Two possibilities can be proposed: On the one hand, the injured network (Figure 1, black arrows) could be restored similarly as pharmacological treatments [38]. On the other hand, a compensatory neural mechanism could be used to bypass the damaged pathway: The cerebello-thalamo-cortical loop (Figure 1, grey arrows) is involved in the control of movements in MA and seems preserved in PD, at least in the early stages of PD [4] and [39].

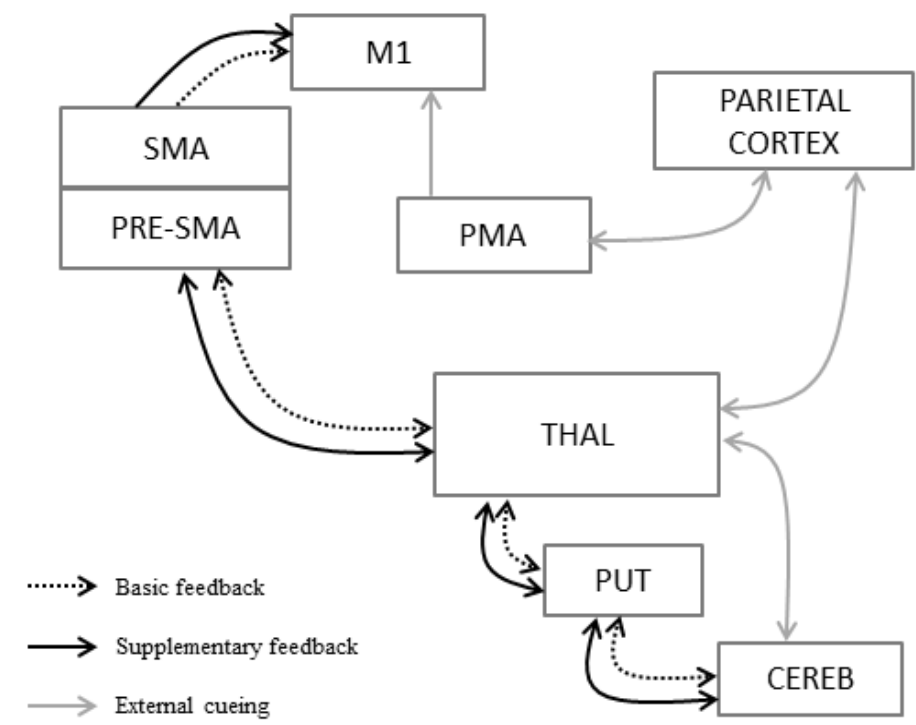

Figure 1. Motor control loops: two options to restore efficient motor control in PD patients (adapted from [4] and [39]). SMA: Supplementary motor area; PRE-SMA: Pre-supplementary motor area; M1: Primary motor area; PMA: Premotor area; THAL: Thalamus; PUT: Putamen (one of the basal ganglia); CEREB: Cerebellum. 


\subsection{Applying supplementary feedback in PD patients "to restore the pathway"}

A deficit of sensory integration in PD has been documented by several studies [40], [41] and [42]. Regarding vision, it has been shown that visual withdrawal leads individuals with PD to increase their movement amplitude [43] and to reduce their velocity [44]. Such effects were not observed in healthy subjects. Longstaff and colleagues [45] proposed that moving slower would be a strategy of PD patients to improve online control, i.e. to be more feedback-dependent [42]. In healthy subjects, the absence of visual feedback can be compensated by kinaesthetic feedback. In PD patients, kinaesthetic feedback does not inform correctly about the hand or upper limb position and movement [42]. Therefore, the absence of visual feedback cannot be fully compensated in PD patients.

Beyond informational processing, applying supplementary feedback in a learning or rehabilitation protocol affects motivation. For example, providing learners with feedback after correct trials, compared with after incorrect trials, results in more effective learning [46]. Interestingly, basal ganglia are critical for supporting learning that is driven by feedback and is motivated by rewards [47]. Foerde and Shohamy [48] reported that the midbrain dopamine system supports feedback-dependent learning processes essential for predicting outcomes. Therefore, applying a real-time supplementary feedback would be relevant for restoring the reward network in PD patients.

\subsection{Applying external cueing in PD patients "to hit another pathway"}

Motor control and coordination are managed by both basal ganglia and cerebellum. Thus, promoting the cerebellum activation to bypass basal ganglia appears as a relevant strategy of rehabilitation. Nombela and colleagues [39] have gathered the findings of various neuroimaging studies in which the auditory external cueing on PD gait was evaluated. Their review provides an accurate description of how music influences motor mechanisms. RAS in music or metronome can act as an external "timer" guiding the execution of the movement and bypassing the dysfunction in striato-thalamo-cortical loop [39] and [49]. When the movement is performed with an external cueing, the online control of movements becomes dependent to this supplementary environmental constraint: the task tends to become similar to a MA task.

\section{Effects on Parkinsonian dysgraphia}

Handwriting is a complex motor activity that requires a great level of expertise. Interestingly, handwriting is particularly altered by PD [50], [51] and [52]. Handwriting disorders in PD are mainly known from the observation of an abnormal reduction in writing size so-called micrographia [53]. Micrographia affects about 50\% of individuals with PD. According to Van Gemmert et al. [54], micrographia would result from an inability to maintain a constant force during handwriting, as well as to 
synchronize wrist and finger movements. Consequently, beyond micrographia, other kinematic and dynamic variables (velocity, dysfluency, i.e. abnormal velocity fluctuations, etc.) would be more systematically altered in Parkinsonian handwriting. Therefore, the term Parkinsonian dysgraphia has been proposed [55] and [56].

What are the causes of PD dysgraphia? On the basis of different models of handwriting, such as the kinematic model [57] and [58] or the neural model of handwriting [59], the "stroke" - the basic motor unit of handwriting - results from the coordinated activity of the muscular system coded as a velocity vector. Interestingly, in these models, only the orientation and amplitude of each velocity vector is processed in the central nervous system and this process is precisely achieved in basal ganglia that are affected in PD (e.g., [60]). Another argument concerns the nature of the task that changes in the course of learning. In beginners, handwriting is like a MA task: they must correct the ongoing movements of the pen thanks to the visual inspection of the generated written trace. Once the characters are learned, the underlying motor pattern is automatized, and handwriting becomes mainly a sequential task in which the writers must check the very rapid succession of the strokes composing a character and the correct sequences of characters composing a word. According to Doyon \& Benali's model [36], this transition relative to the nature of the task would be associated with a switch from the cortico-cerebellar loop, more activated at the early stage of learning, to the cortico-striatal loop, more activated at the latest stage. This assumption was investigated and partially validated in a combined fMRI and kinematic study conducted in healthy adults during a fastlearning of a graphomotor sequence [61]. If confirmed, this may explain both why handwriting is altered in individuals with $\mathrm{PD}$, and why external cueing or supplementary feedback may be particularly relevant for helping them to better control their handwriting.

\subsection{The classical method of handwriting rehabilitation for PD patients}

In 1972, McLennan [53] suggested that the mere presence of parallel lines could allow individuals with $\mathrm{PD}$ to maintain their writing size, thus improving micrographia. This method was tested and validated several times in graphomotor tasks [23] and [62]. Other visual cues, as target points [63] or grid lines [64], has been tested and the authors have shown that they improve both the writing size and width. Furthermore, these cues allow the patients to maintain a correct size during the entire task [62] and [64]. Another method was tested with a graphic tablet [65]. The written trace was displayed in real-time on a screen in front of the writers and their hand and pen were hidden in such a way that participants had visual feedback about the written trace only. This feedback was either normal, smaller, or larger than the actual handwriting. The authors observed that individuals with PD succeed in the visuomotor adaptation by changing the amplitude of their writing movement when the visual feedback was distorted. However, such effects were present when the hand was hidden only and disappeared when the hand was not hidden [66]. Beyond improvements of the spatial feature of handwriting, Nieuwboer and colleagues also demonstrated that freezing of upper limb was improved by visual cueing in a drawing task [62]. 
When comparing the effects of visual cueing and auditory feedback individuals with PD performed better in a graphomotor task when they received an auditory feedback based on verbal instructions or on a spatial sonification than when they realized the task with the presence of visual cues solely [23]. However, we cannot conclude whether the advantage of applying auditory feedback rather than visual cueing results from the use of feedback, the auditory modality, or both. Note that the positive effect of auditory cueing was not observed in a bimanual drawing task by Swinnen and colleagues [67].

\subsection{Towards a new method of handwriting rehabilitation with PD patients based on musical sonification}

The presence of auditory feedback or cueing improves significantly the motor control of individuals with PD. On the one hand, providing a supplementary auditory feedback enriches the patients' perception of their movements and thus enhances their control. On the other hand, providing an external auditory cueing leads the patient to adapt their movements in a very promising way. Is it possible to combine the advantages of both methods?

In this international symposium on computer music multidisciplinary research (CMMR 2017), an individualized approach in the use of RAS was proposed to help PD patients to walk [8]. The principle was to adapt the RAS in real-time to patients step times. The results revealed important individual differences among PD patients with regard to their response to different cueing strategies. The strategy that we are currently evaluating differs from that: we are assessing the effect of abrupt changes of music linked to kinematic thresholds. This method of musical sonification consists of modifying a preselected music according to movement variables: music is distorted when the movement is dysfluent and too slow. The aim is both to improve the perception of movement irregularities (when music changes) and to provide an auditory guidance (when music does not change).

The melodious music associated to a correct movement supplies the writer with an auditory cueing based on musical rhythm. Moreover, melody is also a reward motivating the patients, provided that it is pleasant. This strategy of musical sonification allows patients:

a) To use music as an external cue, considering the advantages of musical rhythm and RAS effects on motor control in PD patients that we have previously described (e.g. [31] and [35])

b) To use music as an auditory feedback informing about the movement correctness if $s /$ he has some difficulties in synchronizing his/her movements with the musical rhythm. Indeed, the ability to synchronize movements with an external rhythm requires a temporal processing on both the metronome and the movement itself. This concomitant processing is potentially affected in PD because it involves the cortico-striatal loop [8]. In the present strategy, writing becomes a pseudo-musical practice. The presence of kinematic thresholds, which can be individualized, leads the writer to manage music with the pen 
like an orchestra conductor with the baton. The writer can stop and start music when s/he decides to. The pen shapes and reshapes music. Consequently, music can be considered as an external goal on which the patients pay attention. Actually, it has been shown that the external focus of attention enhances motor control in PD patients (e.g., [68]).

c) To integrate music as auditory feedback and auditory guidance if they succeed in taking advantage of both supports.

We are currently evaluating this strategy of musical sonification with PD patients and healthy controls. The experiment is designed as a "pre-test/training/post-test" with three different training sessions: one with music, one with musical sonification, and one in silence. During the tests (all in silence), participants were asked to draw loops, write the French word "cellule" (cell) in cursive, and make their own signature (for an illustration, see figure 2).
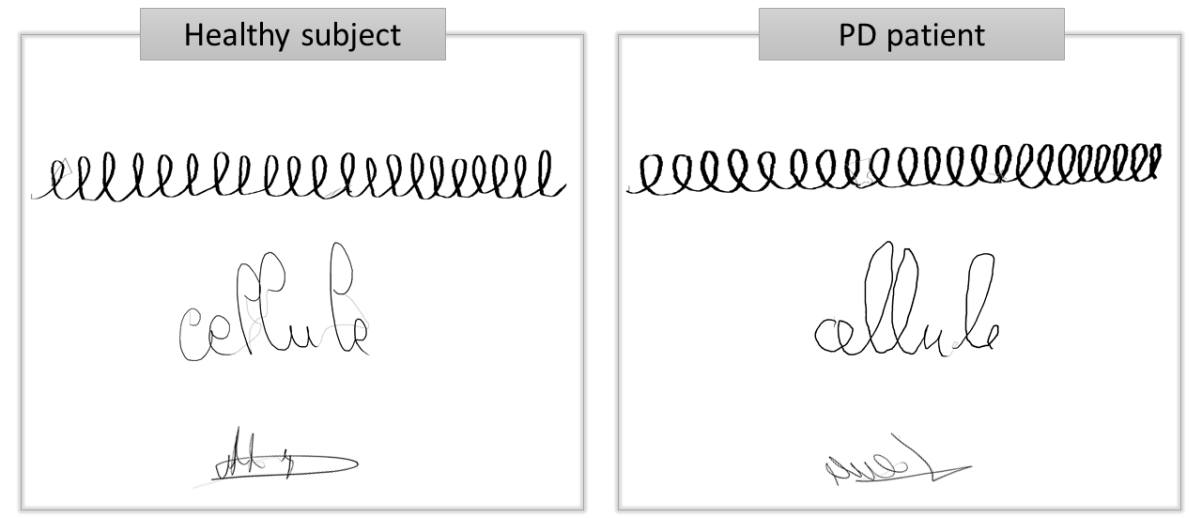

Figure 2. Handwriting tasks produced during the pre-test by a healthy subject (left) and an individual with PD (right).

During the training phases, the participants were required to achieve graphomotor exercises under one of the three conditions (music vs. musical sonification vs. silence). The conditions order was counterbalanced between participants and all participants were tested just before and after each training. When the performance of both groups during each training session (in silence, music or musical sonification) were compared, the very preliminary results (on nine PD patients and nine controls) revealed that writing speed was much higher in both groups under musical sonification. When the differences of performance between post- and pre-test were compared for each training session, both PD patients and controls were faster after musical sonification, both in drawing loops and word writing. These preliminary findings must be interpreted with many cautions. If confirmed, they show that PD patients better perform the task under musical sonification and maintain these improvements at short term. Therefore, musical sonification would be a very promising rehabilitation method for individuals with PD. 


\section{Conclusions}

In the digital age, the interest of handwriting rehabilitation in PD may be limited, although writing a short message on a sticky note or a shopping list is still very useful in the daily life. The advantage for the patient lies rather in the possible transfer of the effects to fine motor rehabilitation. Beyond handwriting, the rehabilitation of the "clumsy hands" that hampers the activities of daily life [69] significantly improves the patients' quality of life, in eating, getting dressed, washing etc. [23] and [27]. Furthermore, motor rehabilitation also slows down the degenerative processes related to $\mathrm{PD}$. The positive effects of external cueing seem to persist over time as if it remains present "inside the head" whereas it is not physically present [4], similarly as basic auditory feedback when playing piano or when producing other audible motor activities [17] and [70]. However, a definite conclusion will be reached when the neural changes underlying the motor improvements following a rehabilitation based on musical sonification will be observed.

Acknowledgments. This research was supported by Grants ANR-16-CONV-0002 (ILCB), ANR-11-LABX-0036 (BLRI), and ANR-11-IDEX-0001-02 (AMIDEX) the Excellence Initiative of Aix-Marseille University. We want to thank Richard Kronland-Martinet, Solvi Ystad et Mitsuko Aramaki (laboratory PRISM), as well as Charles Gondre for the technical development related to the musical sonification.

\section{References}

1. Jankovic, J.: Parkinson's disease: clinical features and diagnosis. J. Neurol. Neurosurg. Psychiatry. 79, 368-376 (2008).

2. Dalla Bella, S., Benoit, C.-E., Farrugia, N., Schwartze, M., Kotz, S.A.: Effects of musically cued gait training in Parkinson's disease: beyond a motor benefit: Auditory cueing in Parkinson's disease. Ann. N. Y. Acad. Sci. 1337, 77-85 (2015).

3. Rodger, M.W.M., Craig, C.M.: Beyond the Metronome: Auditory Events and Music May Afford More than Just Interval Durations as Gait Cues in Parkinson's Disease. Front. Neurosci. 10, (2016).

4. Nieuwboer, A., Rochester, L., Müncks, L., Swinnen, S.P.: Motor learning in Parkinson's disease: limitations and potential for rehabilitation. Parkinsonism Relat. Disord. 15, S53-S58 (2009).

5. Benoit, C.-E., Dalla Bella, S., Farrugia, N., Obrig, H., Mainka, S., Kotz, S.A.: Musically Cued Gait-Training Improves Both Perceptual and Motor Timing in Parkinsonâ€ $€^{\mathrm{TM}_{\mathrm{S}}}$ Disease. Front. Hum. Neurosci. 8, (2014).

6. de Bruin, N., Doan, J.B., Turnbull, G., Suchowersky, O., Bonfield, S., Hu, B., Brown, L.A.: Walking with Music Is a Safe and Viable Tool for Gait Training in Parkinson's Disease: The Effect of a 13-Week Feasibility Study on Single and Dual Task Walking. Park. Dis. 2010, 1-9 (2010).

7. Chen, P.-H., Liou, D.-J., Liou, K.-C., Liang, J.-L., Cheng, S.-J., Shaw, J.-S.: Walking Turns in Parkinson's Disease Patients with Freezing of Gait: The Shortterm Effects of Different Cueing Strategies. Int. J. Gerontol. 10, 71-75 (2016). 
8. Dalla Bella, S., Benoit, C.-E., Farrugia, N., Keller, P.E., Obrig, H., Mainka, S., Kotz, S.A.: Gait improvement via rhythmic stimulation in Parkinson's disease is linked to rhythmic skills. Sci. Rep. 7, 42005 (2017).

9. Delval, A., Defebvre, L., Tard, C.: Freezing during tapping tasks in patients with advanced Parkinson's disease and freezing of gait. PLOS ONE. 12, e0181973 (2017).

10.Hackney, M., Earhart, G.: Effects of dance on movement control in Parkinson's disease: A comparison of Argentine tango and American ballroom. J. Rehabil. Med. 41, 475-481 (2009).

11.Hackney, M.E., Earhart, G.M.: Health-related quality of life and alternative forms of exercise in Parkinson disease. Parkinsonism Relat. Disord. 15, 644-648 (2009).

12.Harro, C., Shoemaker, M., Frey, O., Gamble, A., Harring, K., Karl, K., McDonald, J., Murray, C., Tomassi, E., Van Dyke, J., VanHaistma, R.: The effects of speeddependent treadmill training and rhythmic auditory-cued overground walking on gait function and fall risk in individuals with idiopathic Parkinson\&apos;s disease: A randomized controlled trial. NeuroRehabilitation. 557-572 (2014).

13.Ledger, S., Galvin, R., Lynch, D., Stokes, E.K.: A randomised controlled trial evaluating the effect of an individual auditory cueing device on freezing and gait speed in people with Parkinson's disease. BMC Neurol. 8, (2008).

14.Lee, S.J., Yoo, J.Y., Ryu, J.S., Park, H.K., Chung, S.J.: The Effects of Visual and Auditory Cues on Freezing of Gait in Patients with Parkinson Disease: Am. J. Phys. Med. Rehabil. 91, 2-11 (2012).

15.Lopez, W.O.C., Higuera, C.A.E., Fonoff, E.T., de Oliveira Souza, C., Albicker, U., Martinez, J.A.E.: Listenmee and Listenmee smartphone application: Synchronizing walking to rhythmic auditory cues to improve gait in Parkinson's disease. Hum. Mov. Sci. 37, 147-156 (2014).

16.Rochester, L., Burn, D.J., Woods, G., Godwin, J., Nieuwboer, A.: Does auditory rhythmical cueing improve gait in people with Parkinson's disease and cognitive impairment? A Feasibility study. Mov. Disord. 24, 839-845 (2009).

17.Young, W.R., Rodger, M.W., Craig, C.M.: Auditory observation of stepping actions can cue both spatial and temporal components of gait in Parkinson' s disease patients. Neuropsychologia. 57, 140-153 (2014).

18. Young, W.R., Shreve, L., Quinn, E.J., Craig, C., Bronte-Stewart, H.: Auditory cueing in Parkinson's patients with freezing of gait. What matters most: Actionrelevance or cue-continuity? Neuropsychologia. 87, 54-62 (2016).

19.Baram, Y., Aharon-Peretz, J., Badarny, S., Susel, Z., Schlesinger, I.: Closed-loop auditory feedback for the improvement of gait in patients with Parkinson's disease. J. Neurol. Sci. 363, 104-106 (2016).

20.Carpinella, I., Cattaneo, D., Bonora, G., Bowman, T., Martina, L., Montesano, A., Ferrarin, M.: Wearable Sensor-Based Biofeedback Training for Balance and Gait in Parkinson Disease: A Pilot Randomized Controlled Trial. Arch. Phys. Med. Rehabil. 98, 622-630.e3 (2017).

21.Ginis, P., Heremans, E., Ferrari, A., Bekkers, E.M.J., Canning, C.G., Nieuwboer, A.: External input for gait in people with Parkinson's disease with and without freezing of gait: One size does not fit all. J. Neurol. 264, 1488-1496 (2017).

22.Lohnes, C.A., Earhart, G.M.: The impact of attentional, auditory, and combined cues on walking during single and cognitive dual tasks in Parkinson disease. Gait Posture. 33, 478-483 (2011). 
23.Ringenbach, S.D.R., van Gemmert, A.W.A., Shill, H.A., Stelmach, G.E.: Auditory instructional cues benefit unimanual and bimanual drawing in Parkinson's disease patients. Hum. Mov. Sci. 30, 770-782 (2011).

24.Studer, V., Maestri, R., Clerici, I., Spina, L., Zivi, I., Ferrazzoli, D., Frazzitta, G.: Treadmill Training with Cues and Feedback Improves Gait in People with More Advanced Parkinson's Disease. J. Park. Dis. 7, 729-739 (2017).

25.Welch, R.B., Warren, D.H.: Immediate perceptual response to intersensory discrepancy. Psychol. Bull. 88, 638 (1980).

26.Schmidt, R., Lee, T.: Motor Learning and performance, $5 \mathrm{E}$ with web study guide: from principles to application. Human Kinetics (2013).

27.Nackaerts, E., Vervoort, G., Heremans, E., Smits-Engelsman, B.C.M., Swinnen, S.P., Nieuwboer, A.: Relearning of writing skills in Parkinson's disease: A literature review on influential factors and optimal strategies. Neurosci. Biobehav. Rev. 37, 349-357 (2013).

28.McIntosh, G.C., Brown, S.H., Rice, R.R., Thaut, M.H.: Rhythmic auditory-motor facilitation of gait patterns in patients with Parkinson's disease. J. Neurol. Neurosurg. Psychiatry. 62, 22-26 (1997).

29. Atkinson-Clement, C., Sadat, J., Pinto, S.: Behavioral treatments for speech in Parkinson's disease: meta-analyses and review of the literature. Neurodegener. Dis. Manag. 5, 233-248 (2015).

30.Fujii, S., Wan, C.Y.: The Role of Rhythm in Speech and Language Rehabilitation: The SEP Hypothesis. Front. Hum. Neurosci. 8, (2014).

31.Zatorre, R.J., Chen, J.L., Penhune, V.B.: When the brain plays music: auditorymotor interactions in music perception and production. Nat. Rev. Neurosci. 8, 547-558 (2007).

32. Mainka, S.: Music stimulates muscles, mind, and feelings in one go. Front. Psychol. 6, (2015).

33. Satoh, M., Kuzuhara, S.: Training in Mental Singing while Walking Improves Gait Disturbance in Parkinson\&rsquo;s Disease Patients. Eur. Neurol. 60, 237-243 (2008).

34.Wittwer, J.E., Webster, K.E., Hill, K.: Music and metronome cues produce different effects on gait spatiotemporal measures but not gait variability in healthy older adults. Gait Posture. 37, 219-222 (2013).

35.Sihvonen, A.J., Särkämö, T., Leo, V., Tervaniemi, M., Altenmüller, E., Soinila, S.: Music-based interventions in neurological rehabilitation. Lancet Neurol. 16, 648660 (2017).

36.Doyon, J., Benali, H.: Reorganization and plasticity in the adult brain during learning of motor skills. Curr. Opin. Neurobiol. 15, 161-167 (2005).

37.Doyon, J., Bellec, P., Amsel, R., Penhune, V., Monchi, O., Carrier, J., Lehéricy, S., Benali, H.: Contributions of the basal ganglia and functionally related brain structures to motor learning. Behav. Brain Res. 199, 61-75 (2009).

38.Pinto, S., Mancini, L., Jahanshahi, M., Thornton, J.S., Tripoliti, E., Yousry, T.A., Limousin, P.: Functional magnetic resonance imaging exploration of combined hand and speech movements in Parkinson's disease. Mov. Disord. 26, 2212-2219 (2011).

39.Nombela, C., Hughes, L.E., Owen, A.M., Grahn, J.A.: Into the groove: Can rhythm influence Parkinson's disease? Neurosci. Biobehav. Rev. 37, 2564-2570 (2013). 
40.Berardelli, A., Rothwell, J.C., Thompson, P.D., Hallett, M.: Pathophysiology of bradykinesia in Parkinson's disease. Brain. 124, 2131-2146 (2001).

41.Schneider, J.S., Diamond, S.G., Markham, C.H.: Parkinson's disease: Sensory and motor problems in arms and hands. Neurology. 37, 951-951 (1987).

42.Klockgether, T., Borutta, M., Rapp, H., Spieker, S., Dichgans, J.: A defect of kinesthesia in Parkinson's disease. Mov. Disord. 10, 460-465 (1995).

43. Ondo, W.G., Satija, P.: Withdrawal of visual feedback improves micrographia in Parkinson's disease. Mov. Disord. 22, 2130-2131 (2007).

44.Klockgether, T., Dichgans, J.: Visual control of arm movement in Parkinson's disease. Mov. Disord. 9, 48-56 (1994).

45.Longstaff, M.G., Mahant, P.R., Stacy, M.A., Van Gemmert, A.W., Leis, B.C., Stelmach, G.E.: Discrete and dynamic scaling of the size of continuous graphic movements of parkinsonian patients and elderly controls. J. Neurol. Neurosurg. Psychiatry. 74, 299-304 (2003).

46. Chiviacowsky, S., Wulf, G.: Feedback After Good Trials Enhances Learning. Res. Q. Exerc. Sport. 78, 40-47 (2007).

47.Turner, R.S., Desmurget, M.: Basal ganglia contributions to motor control: a vigorous tutor. Curr. Opin. Neurobiol. 20, 704-716 (2010).

48. Foerde, K., Shohamy, D.: The role of the basal ganglia in learning and memory: insight from Parkinson's disease. Neurobiol. Learn. Mem. 96, 624-636 (2011).

49. Nombela, C., Rae, C.L., Grahn, J.A., Barker, R.A., Owen, A.M., Rowe, J.B.: How often does music and rhythm improve patients' perception of motor symptoms in Parkinson's disease? J. Neurol. 260, 1404-1405 (2013).

50. Margolin, D.I., Wing, A.M.: Agraphia and micrographia: Clinical manifestations of motor programming and performance disorders. Acta Psychol. (Amst.). 54, 263-283 (1983).

51.Lewitt, P.A.: Micrographia as a focal sign of neurological disease. J. Neurol. Neurosurg. Psychiatry. 46, 1152 (1983).

52.Phillips, J.G., Stelmach, G.E., Teasdale, N.: What can indices of handwriting quality tell us about Parkinsonian handwriting? Hum. Mov. Sci. 10, 301-314 (1991).

53.McLennan, J.E., Nakano, K., Tyler, H.R., Schwab, R.S.: Micrographia in Parkinson's disease. J. Neurol. Sci. 15, 141-152 (1972).

54.Van Gemmert, A.W.A., Teulings, H.-L., Contreras-Vidal, J.L., Stelmach, G.E.: Parkinsons disease and the control of size and speed in handwriting. Neuropsychologia. 37, 685-694 (1999).

55.Letanneux, A., Danna, J., Velay, J.-L., Viallet, F., Pinto, S.: From micrographia to Parkinson's disease dysgraphia: Parkinson's Disease Dysgraphia. Mov. Disord. 29, 1467-1475 (2014).

56.Pinto, S., Velay, J.-L.: Handwriting as a marker for PD progression: a shift in paradigm. Neurodegener. Dis. Manag. 5, 367-369 (2015).

57.Plamondon, R.: Errata: A kinematic theory of rapid human movements, Part I. Biol. Cybern. 73, 95 (1995).

58. Plamondon, R.: Errata: A kinematic theory of rapid human movements, Part II. Biol. Cybern. 73, 95 (1995).

59.Grossberg, S., Paine, R.W.: A neural model of cortico-cerebellar interactions during attentive imitation and predictive learning of sequential handwriting movements. Neural Netw. 13, 999-1046 (2000). 
60.Berardelli, A., Hallett, M., Rothwell, J.C., Agostino, R., Manfredi, M., Thompson, P.D., Marsden, C.D.: Single-joint rapid arm movements in normal subjects and in patients with motor disorders. Brain. 119, 661-674 (1996).

61.Swett, B.A., Contreras-Vidal, J.L., Birn, R., Braun, A.: Neural Substrates of Graphomotor Sequence Learning: A Combined fMRI and Kinematic Study. J. Neurophysiol. 103, 3366-3377 (2010).

62.Nieuwboer, A., Vercruysse, S., Feys, P., Levin, O., Spildooren, J., Swinnen, S.: Upper limb movement interruptions are correlated to freezing of gait in Parkinson's disease. Eur. J. Neurosci. 29, 1422-1430 (2009).

63. Oliveira, R.M., Gurd, J.M., Nixon, P., Marshall, J.C., Passingham, R.E.: Micrographia in Parkinson's disease: the effect of providing external cues. J. Neurol. Neurosurg. Psychiatry. 63, 429-433 (1997).

64.Bryant, M., Rintala, D., Lai, E., Protas, E.: An investigation of two interventions for micrographia in individuals with Parkinson's disease. Clin. Rehabil. 24, 10211026 (2010).

65.Contreras-Vidal, J.L., Teulings, H.-L., Stelmach, G.E., Adler, C.H.: Adaptation to changes in vertical display gain during handwriting in Parkinson's disease patients, elderly and young controls. Parkinsonism Relat. Disord. 9, 77-84 (2002).

66.Teulings, H.L., Contreras-Vidal, J.L., Stelmach, G.E., Adler, C.H.: Adaptation of handwriting size under distorted visual feedback in patients with Parkinson's disease and elderly and young controls. J. Neurol. Neurosurg. Psychiatry. 72, 315324 (2002).

67.Swinnen, S.P., Steyvers, M., Van Den Bergh, L., Stelmach, G.E.: Motor learning and Parkinson's disease: refinement of within-limb and between-limb coordination as a result of practice. Behav. Brain Res. 111, 45-59 (2000).

68. Wulf, G., Landers, M., Lewthwaite, R., Toöllner, T.: External focus instructions reduce postural instability in individuals with Parkinson disease. Phys. Ther. 89, $162-168$ (2016).

69.Jankovic, J.: Pathophysiology and clinical assessment of motor symptoms in Parkinson's disease. Handb. Park. Dis. (1987).

70.Bangert, M., Peschel, T., Schlaug, G., Rotte, M., Drescher, D., Hinrichs, H., Heinze, H.-J., Altenmüller, E.: Shared networks for auditory and motor processing in professional pianists: Evidence from fMRI conjunction. NeuroImage. 30, 917926 (2006). 